\title{
UTILIZAÇÃO DO FARELO DE CANOLA EM DIETAS PARA SUÍNOS EM CRESCIMENTO E TERMINAÇÃO
}

\author{
UTILIZATION OF CANOLA MEAL IN DIETS OF GROWING AND FINISHING PIGS
}

\author{
Zanotto, D.L. ${ }^{1 *}$, J.V. Ludke ${ }^{1 A}$, A.L. Guidoni ${ }^{1 A}$, P.C. Gomes ${ }^{2}$, P.A.R. Brum ${ }^{1 A}$ e L.C. Ajala ${ }^{1 A}$ \\ ${ }^{1} E$ mbrapa Suínos e Aves. C.P. 21. CEP 89700-000. Concórdia. Santa Catarina. Brasil. \\ *zanotto@cnpsa.embrapa.br, Asac@cnpsa.embrapa.br \\ 2Departamento de Zootecnia-CCA. Universidade Federal de Viçosa. Minas Gerais. Brasil. pcgomes@ufv.br
}

\section{PalaVRas chaVe adicionais}

Alimento alternativo. Carcaça. Desempenho.

\section{RESUMO}

Foram utilizados 90 suínos (dos $25,8 \mathrm{~kg}$ até o abate aos $102,6 \mathrm{~kg}$ ) para avaliar o efeito do uso do farelo de canola nas rações. O delineamento experimental foi em blocos casualizados em esquema fatorial com cinco níveis de farelo $\mathrm{x}$ dois sexos e três repetições. $O$ farelo de canola foi incluido em níveis de 20,40,60 e $80 \%$ de substituição do farelo de soja tendo como base a ração referência (milho e farelo de soja) e mantendo simultaneamente as dietas experimentais isoprotéicas e isoenergéticas. Parâmetros de desempenho no crescimento, terminação e total, e de carcaça ao abate foram avaliados. Foi observado efeito de interação entre tratamento e sexo para a conversão alimentar em todas as fases. $\mathrm{Na}$ terminação e no período total foi observado para tratamento um efeito quadrático no consumo. Para o ganho de peso foi caracterizado efeito quadrático apenas no período total. Os machos castrados apresentaram maior consumo e ganho de peso em todas as fases. Apenas os tratamentos e sexo tiveram efeito sobre a carcaça sendo verificada ausência de interação. É recomendado o nível de substituição de $40 \%$ do farelo de soja da dieta referência que proporciona alto ganho de peso e têm associada a produção de carcaças mais pesadas resultando em maior produção estimada de carne. Porém, as carcaças apresentam maior espessura de toucinho e menor porcentagem de carne.

\section{SUMMARY}

Ninety pigs (from $25.8 \mathrm{~kg}$ until slaugther at

Recibido: 15-11-07. Aceptado: 5-3-09.

\author{
AditTIONAL KEYWORDS \\ Alternative feedstuff. Carcass. Performance.
}

$102.6 \mathrm{~kg}$ ) were used to evaluate the influence of canola meal in swine diets. A randomized block design was arranged in a factorial model with five canola meal levels, two sexes and three replications. Canola meal was included at 20, 40, 60 and $80 \%$ substituition of soybean meal considering the reference diet (corn and soybean meal) and keeping simultaneously experimental diets similar in protein and metabolizable energy. Growing, finishing and total period performance and carcass traits were evaluated. Interaction between treatment and gender were observed for fed to gain ratio in all of the periods evaluated. At finishing and total period a quadratic effect of treatment were observed for feed consumption. For weight gain were characterized a quadratic effect for treatment only in the total period. Barrows presented higher feed consumption and weight gain in all evaluated periods. Only treatment and gender had effect on carcass characteristics without interaction effects. Substituition level of $40 \%$ soybean meal in reference diet were recomended. This level yields a high weight gain and at consequence heavier carcasses resulting in higher estimated meat production but greater backfat depth and lower meat yield.

\section{INTRODUÇÃO}

A substituição do farelo de soja por farelo de canola nas dietas de suínos tem sido objeto de vários estudos. Bourdon e Aumaitre (1990) evidenciaram a possi- 
bilidade de substituição apenas parcial, sem que houvesse comprometimento no desempenho dos animais. Gomes et al. (1998) observaram que é viável a inclusão de 15\% de farelo de canola na dieta de suínos em terminação, enquanto que Baidoo et al. (1987) verificaram que a inclusão pode ser de até $9 \%$ ( $50 \%$ de substituição) e $12 \%$ (100\% de substituição) para suínos em crescimento e terminação, respectivamente, sem afetar o desempenho. O Canola Council of Canada (1989) com base nos experimentos realizados na década de 80 recomendou em $12 \%$ o nível máximo de inclusão de farelo de canola na dieta de suínos em crescimento e $18 \%$ nas dietas de suínos em terminação. Thacker (1990) recomendou que o farelo de canola substituísse apenas $50 \%$ da fonte protéica em dietas de crescimento e terminação de suínos. Brand et al. (2001) determinaram o nível de inclusão de farelo de canola em $24 \%$ nas dietas para suínos dos 25 aos $84 \mathrm{~kg}$ como adequado, sem afetar o desempenho.

Rojo et al. (2001) avaliaram o potencial de substituição parcial (50\%) ou total (100\%) do farelo de soja por farelo de canola e seus efeitos em suínos abatidos aos $100 \mathrm{~kg}$ de peso vivo relatando que o rendimento de carcaça, a porcentagem de carne e a espessura de toucinho não foram afetados pelos tratamentos. Gomes et al. (1998), Schöne et al.(2002), Roth-Maier et al.(2004) e Thacker e Newkirk (2005) também não encontraram efeito de níveis elevados de farelo de canola em dietas de suínos sobre as características de carcaça avaliadas. Porém, Brand et al. (2001) avaliando carcaças de suínos leves (até $85 \mathrm{~kg}$ de peso vivo) em função da inclusão de níveis altos de farelo de canola (24\% de farelo gerado via extração por solvente e $29,2 \%$ de farelo obtido via extração por prensa) determinaram redução na espessura de toucinho, aumento da porcentagem de carne na carcaça e redução no rendimento de carcaça.

Um experimento foi realizado com o objetivo de avaliar a viabilidade do uso do farelo de canola em dietas isoenergéticas e isoprotéicas de suínos para engorda nas fases de crescimento e terminação quando em substituição ao farelo de soja.

\section{MATERIALE MÉTODOS}

O experimento foi realizado na Embrapa Suínos e Aves, Concórdia, SC, Brasil. Foram utilizados 90 suínos de abate, metade fêmeas e metade machos castrados, oriundos do cruzamento de fêmeas F1 (Landrace x Large White) cobertas por macho reprodutor (Large White x Duroc). O peso médio inicial dos animais foi de $25,8 \mathrm{~kg}$ e o peso médio ao final do experimento foi de $102,6 \mathrm{~kg}$. O período experimental teve a duração de 84 dias, sendo 42 dias para a fase de crescimento e 42 dias para a fase de terminação. Durante o

Tabela I. Composição nutricional (\%) dos ingredientes utilizados no experimento de desempenho. (Nutritional composition (\%) of the ingredients used in performance trial).

\begin{tabular}{lccr}
\hline Composição nutricional $^{1}$ & FC & FS & M \\
\hline EM (Kcal/kg) & $1692^{*}$ & 3242 & 3332 \\
Matéria seca & 90,59 & 90,23 & 88,41 \\
Proteína bruta & 36,43 & 44,25 & 8,30 \\
Extrato etéreo & 0,90 & 1,20 & 3,60 \\
Fibra bruta & 15,29 & 7,30 & 2,17 \\
Extr. não nitrogenados & 32,16 & 30,75 & 70,11 \\
Cinzas & 5,81 & 6,73 & 4,23 \\
Lisina total & 2,33 & 2,71 & 0,27 \\
Metionina+cistina & 1,94 & 1,08 & 0,33 \\
Triptofano & 0,46 & 0,74 & 0,06 \\
Treonina & 1,47 & 1,60 & 0,27 \\
Valina & 1,89 & 1,91 & 0,35 \\
Isoleucina & 1,53 & 1,86 & 0,25 \\
Leucina & 2,73 & 3,17 & 0,88 \\
Cálcio & 0,55 & 0,23 & 0,02 \\
Fósforo total & 0,81 & 0,60 & 0,25 \\
Fósforo disponível & 0,20 & 0,20 & 0,09 \\
\hline
\end{tabular}

$\mathrm{FC}=$ farelo de canola; $\mathrm{FS}=$ farelo de soja; $\mathrm{M}=$ milho. ${ }^{1}$ Análises via Laboratório de Análises Fisico-Químicas da Embrapa Suínos e Aves.

*Determinado através de ensaio de metabolismo. 
experimento a água e as rações experimentais foram fornecidas aos suínos à vontade. Os animais foram agrupados por sexo e por peso inicial, em baias com piso semi-ripado, equipadas com comedouro automático e bebedouro tipo chupeta. Na tabela I está apresentada a composição bromatológica do farelo de canola (FC), farelo de soja (FS) e milho (M) utilizados nas dietas experimentais cuja análise foi realizada no Laboratório de Nutrição Animal da Embrapa Suínos e Aves segundo os métodos descritos na AOAC (1990). Um ensaio de metabolismo foi realizado e o valor de energía metabolizável do farelo de canola foi determinado visando a formulação das dietas experimentais. O ácido erúcico analisado no farelo de canola totalizou $0,17 \%$ e os glicosinolatos se apresentaram uma concentração de 5,0 $\mathrm{mmol} / \mathrm{g}$ e classificam o farelo de canola como intermediário entre de muito baixo a baixo teor mas, esta concentração ainda está acima da recomendação de limite máximo de $2,5 \mu \mathrm{mol} / \mathrm{g}$ de farelo (Bell et al., 1991).

Foram estabelecidos cinco tratamentos nos quais foram avaliados níveis de substituição do farelo de soja por farelo de canola mantendo constantes, por fase, o nível de proteína bruta e energía metabolizável. O desenho experimental aplicado foi um modelo fatorial (dois sexos x cinco dietas experimentais) com três repetições ou blocos hierarquizados dentro de cada sexo, sendo as dietas aleatorizadas em cada bloco. A unidade experimental foi a baia contendo três suínos de mesmo sexo e homogêneos no peso vivo. Os níveis de substituição aplicados de 20,40,60 e 80\% foram em relação à participação do farelo de soja na dieta Referência isenta de farelo de canola. Isto resultou nos níveis de inclusão fixos de $3,89 \%$ e de $2,85 \%$ de farelo de canola para cada $20 \%$ de substituição do farelo de soja presente na ração referência, respectivamente, nas dietas das fases de crescimento e terminação. Assim, conforme apresentado na tabela II, para os níveis de 20,40, 60 e $80 \%$ de substituição do farelo de soja por farelo de canola, tanto na fase de crescimento quanto na fase de terminação, a porcentagem de proteína bruta proveniente do farelo de canola foi, respectivamente, de $15,9,31,1,45,6$ e 59,6\% quando consideradas as fontes protéicas (farelo de canola e farelo de soja) utilizadas nas dietas. Nas dietas de crescimento e terminação, apresentadas na tabela III, os níveis de

Tabela II. Relações calculadas na substituição do farelo de soja da dieta referência por farelo de canola nas fases de crescimento e terminação e as respectivas concentrações de glicosinolatos nas dietas por nível de substituição. (Calculated relationship in substitution of soybean meal in reference diet by canola meal in growing and finishing phases and the levels of glucosinolates in diets by levels of substitution).

\begin{tabular}{ccccccc}
\hline $\begin{array}{c}\text { Substituição do } \\
\text { FS por FC, \% }\end{array}$ & $\begin{array}{c}\text { Nível de FC na dieta, \% } \\
\text { crescimento }\end{array}$ & $\begin{array}{c}\text { Relação } \\
\text { terminação }\end{array}$ & $\begin{array}{c}\text { RC/(FC + FS) em } \\
\text { peso, \% }\end{array}$ & $\begin{array}{c}\text { Glicosinolatos totais } \\
\text { proteína, \% }\end{array}$ & crescimento & terminação \\
\hline 0 & 0,0 & 0,0 & 0,0 & 0,0 & 0,0 & 0,0 \\
20 & 3,89 & 2,85 & 18,9 & 15,9 & 194,5 & 142,5 \\
40 & 7,78 & 5,70 & 35,7 & 31,1 & 389,0 & 285,0 \\
60 & 11,67 & 8,54 & 50,9 & 45,6 & 582,0 & 427,0 \\
80 & 15,56 & 11,39 & 64,5 & 59,6 & 778,0 & 569,5 \\
\hline
\end{tabular}

FS= Farelo de soja, FC= Farelo de canola. ${ }^{1}$ Participação percentual (em peso e em proteína bruta) do farelo de canola no total das fontes protéicas na dieta. Os valores apresentados para cada nível são iguais na fase de crescimento e terminação. ${ }^{2} \mu \mathrm{mol} / \mathrm{kg}$ de dieta. 
proteína bruta adotados, respectivamente 15 e $13 \%$, foram escolhidos para se estabelecer o potencial de uso do farelo de canola em dietas com baixo nível protéico frente ao alto potencial de ganho de peso dos animais utilizados no experimento.

Para o estudo dos efeitos das causas de variação (tratamento e sexo) foram avaliadas as fases de crescimento, terminação e período total considerando o ganho de peso diário (GPD, g/dia), consumo de ração diário (CRD, g/dia) e conversão alimentar (CA, g/ g). As pesagens dos animais foram realizadas de 14 em 14 dias sempre às 6:00 horas da manhã após um período de 12 horas de jejum de sólidos. Ao final da fase de terminação,

Tabela III. Composição (\%) das dietas experimentais geradas a partir do cálculo da substituição do farelo de soja das respectivas dietas referências pelo farelo de canola nos níveis indicados. (Composition (\%) of the experimental diets calculated by substitution of soybean meal of the respective reference diets by canola meal at the indicated levels).

\begin{tabular}{|c|c|c|c|c|c|c|c|c|c|c|}
\hline & \multicolumn{10}{|c|}{ Nivel de substituição do FS da dieta referência pelo FC (\%) } \\
\hline & \multicolumn{5}{|c|}{ Dietas de crescimento } & \multicolumn{5}{|c|}{ Dietas de terminação } \\
\hline & Ref. & 20 & 40 & 60 & 80 & Ref. & 20 & 40 & 60 & 80 \\
\hline Milho moído & 77,13 & 74,74 & 72,35 & 69,96 & 67,57 & 82,72 & 80,99 & 79,24 & 77,49 & 75,74 \\
\hline Farelo de canola & 0,00 & 3,89 & 7,78 & 11,67 & 15,56 & 0,00 & 2,85 & 5,70 & 8,54 & 11,39 \\
\hline Farelo de soja & 19,43 & 16,71 & 13,99 & 11,27 & 8,55 & 14,24 & 12,24 & 10,24 & 8,25 & 6,25 \\
\hline Óleo de soja & 0,76 & 2,05 & 3,34 & 4,63 & 5,92 & 0,84 & 1,79 & 2,73 & 3,68 & 4,63 \\
\hline Calcário calcítico & 0,98 & 0,97 & 0,96 & 0,95 & 0,94 & 1,01 & 1,00 & 0,99 & 0,98 & 0,97 \\
\hline Fosfato bicálcico & 1,04 & 0,98 & 0,93 & 0,87 & 0,82 & 0,57 & 0,52 & 0,48 & 0,44 & 0,40 \\
\hline L-Lisina $\mathrm{HCl}$ & 0,02 & 0,02 & 0,01 & 0,01 & 0,00 & 0,00 & 0,00 & 0,00 & 0,00 & 0,00 \\
\hline Ingredientes fixos ${ }^{1}$ & 0,64 & 0,64 & 0,64 & 0,64 & 0,64 & 0,62 & 0,62 & 0,62 & 0,62 & 0,62 \\
\hline \multicolumn{11}{|c|}{ Composição nutricional } \\
\hline EMA, kcal $/ \mathrm{kg}^{2}$ & 3260 & 3260 & 3260 & 3260 & 3260 & 3275 & 3275 & 3275 & 3275 & 3275 \\
\hline Proteína bruta & 15,0 & 15,0 & 15,0 & 15,0 & 15,0 & 13,0 & 13,0 & 13,0 & 13,0 & 13,0 \\
\hline Lisina total & 0,75 & 0,76 & 0,76 & 0,77 & 0,78 & 0,60 & 0,61 & 0,62 & 0,63 & 0,64 \\
\hline Met.+Cis. & 0,46 & 0,50 & 0,54 & 0,58 & 0,62 & 0,42 & 0,45 & 0,48 & 0,50 & 0,53 \\
\hline Triptofano & 0,19 & 0,19 & 0,18 & 0,18 & 0,18 & 0,15 & 0,15 & 0,15 & 0,15 & 0,14 \\
\hline Treonina & 0,52 & 0,53 & 0,53 & 0,54 & 0,55 & 0,45 & 0,46 & 0,46 & 0,47 & 0,47 \\
\hline Valina & 0,64 & 0,65 & 0,67 & 0,68 & 0,69 & 0,56 & 0,57 & 0,58 & 0,59 & 0,60 \\
\hline Isoleucina & 0,55 & 0,56 & 0,56 & 0,56 & 0,57 & 0,47 & 0,47 & 0,48 & 0,48 & 0,48 \\
\hline Leucina & 1,29 & 1,29 & 1,29 & 1,29 & 1,29 & 1,18 & 1,18 & 1,18 & 1,18 & 1,18 \\
\hline Cálcio & 0,60 & 0,60 & 0,60 & 0,60 & 0,60 & 0,50 & 0,50 & 0,50 & 0,50 & 0,50 \\
\hline Fósforo total & 0,50 & 0,50 & 0,50 & 0,50 & 0,50 & 0,40 & 0,40 & 0,40 & 0,40 & 0,40 \\
\hline Fósforo disponible & 0,30 & 0,29 & 0,28 & 0,27 & 0,26 & 0,19 & 0,19 & 0,18 & 0,18 & 0,17 \\
\hline Fibra bruta & 2,76 & 3,15 & 3,54 & 3,93 & 4,32 & 2,59 & 2,88 & 3,16 & 3,45 & 3,73 \\
\hline
\end{tabular}

${ }^{1}$ Níveis de inclusão: Cloreto de colina (60\%) - 0,05\%; Sal comum - 0,35\%; Premix vitamínico - 0,10\%; Premix mineral $-0,10 \%$ na fase de crescimento e $0,08 \%$ na fase de terminação; Antioxidante - 0,01\%; Antibiótico - 0,03\%. Níveis de garantia por kg de Premix vitamínico: 6000000 UI vit. A, 1500000 UI vit. $D_{3}, 15000$ UI vit $E, 1500 \mathrm{mg}$ vit. $K_{3}, 1350 \mathrm{mg}$ vit. $B_{1}, 4000 \mathrm{mg}$ vit. $B_{2}, 2000 \mathrm{mg}$ vit. $B_{6}, 20000 \mathrm{mg}$ vit. $B_{12}$, $80 \mathrm{mg}$ biotina, $600 \mathrm{mg}$ ácido fólico, $9350 \mathrm{mg}$ ácido pantotênico, $20000 \mathrm{mg}$ ácido nicotínico, $300 \mathrm{mg}$ Se. Níveis de garantia por kg de Premix mineral: 1500 mg I, 1000 mg Co, 10000 mg Cu, 100000 mg Zn, 100000 $\mathrm{mg} \mathrm{Fe}, 40000 \mathrm{mg} \mathrm{Mn}$.

EMA: Energia metabolizável aparente. 
após a última pesagem, os suínos foram embarcados apresentando um jejum de 14 horas e transportados até o abatedouro, distante $11 \mathrm{~km}$ do local do experimento, para abate após duas horas de descanso. As características de carcaça avaliadas foram peso de carcaça quente (PC, $\mathrm{kg})$, espessura de toucinho $(\mathrm{ET}, \mathrm{mm})$ e profundidade de lombo (PL, mm) e com estes dados foi calculado o rendimento de carcaça ( $\mathrm{RC}, \%)$, o rendimento estimado de carne (REC, \%) e a produção estimada de carne (PEC, kg). No abatedouro, o PC foi medido no intervalo de cinco minutos após a evisceração com o uso de balança digital industrial (precisão de 50 gramas) inserida na linha de abate, com a nora mantida em ritmo constante visando o deslocamento das carcaças à câmara fria. O valor obtido e registrado via eletrônica para cada carcaça previamente identificada representa o peso da carcaça do suíno abatido e eviscerado isento de cabeça, papada, banha rama, cauda e patas. Com o PC e o último peso vivo registrado ao final do experimento foi calculado o RC para cada suíno. Após a divisão simétrica das carcaças no sentido longitudinal, a ET e a PL foram medidas na meia carcaça esquerda com o uso de equipamento HGP4 (Hennessy Grade Probe 4) posicionado e inserido de forma padronizada no ponto $\mathrm{P}_{2}$ (uma sonda é inserida em ângulo reto com auxílio de esquadro sinalizador acoplado ao equipamento, na posição entre a última e penúltima costela a $6,5 \mathrm{~cm}$ da linha de corte da meia carcaça). Para cada carcaça com os valores de ET e PL medidos foram gerados os valores de REC segundo a equação 61,475 $-0,572 \times \mathrm{ET}+0,083 \times$ PL. A produção total estimada de carne (PEC, kg) por carcaça avaliada foi calculada através da multiplicação do peso da carcaça quente (PC, $\mathrm{kg}$ ) pelo rendimento estimado de carne (REC, $\%)$.

As variáveis avaliadas foram submetidas à análise de variância dos dados utilizando o método de quadrados mínimos. O modelo matemático adotado referente à análise dos parâmetros foi:

$$
Y_{i j k l}=\mu+C_{i}+S_{j}+B_{k} \times\left(S_{j}\right)+(S \times C)_{i j}+\varepsilon_{i j k l}
$$

onde:

$\mu$ é a média geral,

$C_{i}$ é o efeito do tratamento com $i=1,2,3,4$ e 5 ,

$S_{j}$ é o efeito de sexo com $\mathrm{j}=1$ para machos castrados e 2 para fêmeas,

B é o efeito de bloco com $k=1,2$ e 3 alinhado dentro de cada sexo,

$(\mathrm{S} \times \mathrm{C})_{\mathrm{ij}}$ é a interação entre sexo e tratamento e $\varepsilon_{\mathrm{ijkl}}$ é o erro experimental suposto aleatório e de distribuição normal.

Comparações entre médias das cinco dietas foram feitas por análise de regressão polinomial. A significância dos componentes linear e quadrático foi realizada utilizando-se o teste F. Equações de regressão apropriadas foram ajustadas e seus coeficientes de determinação foram obtidos como a razão da soma de quadrados para o componente linear ou quadrático e a soma de quadrados para rações. A significância das demais hipóteses estatísticas de interesse (efeitos de sexo e da interação entre sexo e tratamentos) foi verificada com o uso do teste $\mathrm{F}$ da análise de variância. As análises foram efetuadas utilizando o procedimento GLM (General Linear Models) do programa estatístico SAS (SAS, 1993). Simultameamente as médias foram comparadas pelo teste $\mathrm{t}$ de Student ao nível de $5 \%$ de probabilidade.

\section{RESULTADOSEDISCUSSÃO}

A análise de variância para os parâmetros de ganho de peso diário e consumo de ração diário e as médias ajustadas com o erro padrão da média estão apresentadas nas tabelas IV e V, respectivamente. Na fase de crescimento não foi verificado efeito de tratamento sobre o ganho de peso médio diário ( $\mathrm{p}=0,3968)$ e consumo diário de ração $(p=0,4737)$. Estes resultados estão em conformidade com os relatados por Li et al. 


\section{ZANOTTO, LUDKE, GUIDONI, GOMES, BRUME AJALA}

Tabela IV. Análise da variância para o ganho de peso e consumo de ração em função dos tratamentos e sexo. (Analysis of variance for weight gain and feed consumption considering the treatments and sex).

\begin{tabular}{|c|c|c|c|c|c|c|c|}
\hline & \multicolumn{7}{|c|}{ Análise estatística (valores de $p$ ) } \\
\hline & \multicolumn{3}{|c|}{ Ganho de peso, g/dia } & \multicolumn{4}{|c|}{ Consumo de ração, g/dia } \\
\hline & crescimento & o terminação & o período total & \multicolumn{4}{|c|}{ crescimento terminação período total } \\
\hline Sexo & 0,0100 & 0,0036 & 0,0005 & 0,0048 & 0,0001 & & 0001 \\
\hline Tratamento & 0,3968 & 0,3340 & 0,1995 & 0,4737 & 0,1531 & & 1677 \\
\hline Efeito linear & 0,4264 & 0,4421 & 0,8137 & 0,5736 & 0,2355 & & 4318 \\
\hline Efeito quadrático & 0,0981 & 0,1374 & 0,0382 & 0,2095 & 0,0752 & & 439 \\
\hline \multirow[t]{2}{*}{ Interação SxT } & 0,1754 & 0,8803 & 0,4803 & 0,2038 & 0,8938 & & 4768 \\
\hline & \multicolumn{7}{|c|}{ Características descritivas } \\
\hline $\mathrm{R}^{2}$ do modelo & 72,86 & 64,67 & 77,90 & 81,17 & 79,62 & & 5,57 \\
\hline C.V. (\%) & 7,61 & 9,12 & 6,10 & 6,78 & 8,05 & & 86 \\
\hline Desvio padrão & 59,5 & 95 & 56,0 & 131 & 257 & & 50 \\
\hline \multirow[t]{2}{*}{ Média geral } & $782 \pm 16$ & $1046 \pm 22$ & $914 \pm 16$ & $1938 \pm 41$ & $3190 \pm 77$ & & $4 \pm 54$ \\
\hline & \multicolumn{7}{|c|}{ Análise de regressão } \\
\hline \multicolumn{2}{|l|}{ Parâmetro } & Período & \multicolumn{3}{|c|}{ Equação } & $\mathrm{R}^{2}$ & Nível \\
\hline \multicolumn{2}{|c|}{ Ganho de peso, g/dia } & total & \multicolumn{3}{|c|}{$y=889,46+280,56 x-364,56 x^{2}$} & 82,39 & $38,5 \%$ \\
\hline \multicolumn{2}{|c|}{ Consumo de ração, g/dia } & erminação & \multicolumn{3}{|c|}{$y=2780,83+1487,62 x-2134,83 x^{2}$} & 74,25 & $34,8 \%$ \\
\hline \multicolumn{2}{|c|}{ Consumo de ração, g/dia } & total & \multicolumn{3}{|c|}{$y=2533,2+622,18 x-905,13 x^{2}$} & 78,91 & $34,4 \%$ \\
\hline
\end{tabular}

Tabela $V$. Médias e desvio padrão para o ganho de peso diário ( $\mathrm{g} /$ dia) e consumo médio diário ( $\mathrm{g} /$ dia) considerando o nivel de substituição do farelo de soja da dieta referência pelo farelo de canola e sexo. (Means and standard deviation for average daily weight gain and average daily feed consumption considering the level of soybean meal substituition in the reference diet by canola meal and sex).

\begin{tabular}{|c|c|c|c|c|c|c|}
\hline \multirow{4}{*}{$\begin{array}{c}\text { Fonte de variação } \\
\text { Nível de } \\
\text { substituição, \% }\end{array}$} & \multicolumn{6}{|c|}{ Desempenho durante as fases do período experimental } \\
\hline & \multicolumn{3}{|c|}{ Ganho de peso, g/dia } & \multicolumn{3}{|c|}{ Consumo de ração, g/dia } \\
\hline & crescimento & terminação & período total & crescimento & terminação & período total \\
\hline & & & & & & \\
\hline 0 & $754 \pm 47$ & $1037 \pm 57$ & $894 \pm 41^{\mathrm{ab}}$ & $1908 \pm 152$ & $3206 \pm 201^{\mathrm{ab}}$ & $2533 \pm 158^{a b}$ \\
\hline 20 & 77 & 105 & 913 & 84 & 3210 & 2562 \\
\hline 40 & 8 & 11 & 960 & 196 & 339 & $75^{\mathrm{a}}$ \\
\hline 60 & 82 & 102 & 923 & 18 & 312 & 257 \\
\hline 80 & $764 \pm 34$ & $995 \pm 59$ & $860 \pm 39^{b}$ & $1896 \pm 86$ & $2992 \pm 196^{b}$ & $2444 \pm 131^{b}$ \\
\hline \multicolumn{7}{|l|}{ Sexo } \\
\hline Machos castrados & s $821 \pm 17^{a}$ & 1117 & 966 & 20 & $0^{a}$ & $2749 \pm 47^{a}$ \\
\hline Fêmeas & $748 \pm 21^{b}$ & $970 \pm 30^{\mathrm{b}}$ & $861 \pm 20^{b}$ & $1855 \pm 49^{b}$ & $2875 \pm 83^{b}$ & $2367 \pm 56^{b}$ \\
\hline
\end{tabular}

Dentro da mesma fonte de variação (nível de substituição ou sexo) em cada coluna as médias com letras distintas diferem $(p<0,05)$ pelo teste $t$ de Student.

Archivos de zootecnia vol. 58, núm. 224, p. 722. 


\section{FARELO DE CANOLA EM DIETAS PARA SUÍNOS EM CRESCIMENTO E TERMINAÇÃO}

(2000) porém, são diferentes dos relatados por Baidoo et al. (1987) que recomendam a substituição apenas parcial do farelo de soja por farelo de canola nesta fase. RothMaier et al. (2004) determinaram que uma substituição parcial do farelo de soja por farelo de canola condiciona a ganho de peso maior quando comparado às dietas com farelo de soja ou com farelo de canola exclusivamente. No presente experimento foi observado efeito significativo para sexo no ganho de peso diário $(\mathrm{p}=0,010)$ e consumo diário de ração $(p=0,0048)$. Os machos castrados ganharam 9,8\% mais peso e consumiram $9,7 \%$ mais ração que as fêmeas. Conforme apresentado na tabela VI, para este período, na conversão alimentar foi verificada interação $(p=0,1045)$ entre tratamento e sexo com regressão cúbica significativa $(\mathrm{p}=0,050)$ para machos castra$\operatorname{dos}\left(\mathrm{y}=2,56-1,58 \mathrm{X}+4,68 \mathrm{X}^{2}-3,54 \mathrm{X}^{3}, \mathrm{R}^{2}=\right.$
97,61) e não significância $(p>0,05)$ para fêmeas. Para os machos castrados existem dois pontos relevantes para a conversão alimentar: 1) uma estimativa de mínima cujo valor é de 2,401 e determinado ao nível de $22,75 \%$ de substituição do farelo de soja da dieta referência por farelo de canola e, 2) uma estimativa de máxima conversão alimentar cujo valor é de 2,538 e determinado ao nível de $65,38 \%$ de substituição. Este resultado indica de forma clara que, durante os 42 dias nos quais os animais foram submetidos às dietas, para os machos castrados existe uma influência do nível de farelo de canola que se expressa sobre a conversão alimentar pois, até o nível de $22,75 \%$ de substituição existe um benefício pela sua presença na dieta. A partir deste nível até o valor limite de $65,38 \%$ de substituição do farelo de soja por farelo de canola a converão alimentar vai piorando

Tabela VI. Análise da variância para a conversão alimentar em função dos tratamentos e sexo. (Analysis of variance for feed to gain ratio considering the treatments and sex).

\begin{tabular}{|c|c|c|c|}
\hline & $\begin{array}{l}\text { Análise estatí } \\
\text { crescimento } \\
25,8 \text { a } 58,7 \mathrm{~kg}\end{array}$ & $\begin{array}{l}\text { a conversão alin } \\
\text { terminação } \\
58,7 \text { a } 102,6 \mathrm{~kg}\end{array}$ & $\begin{array}{c}\text { /g (valores de } p) \\
\text { período total } \\
25,8 \text { a } 102,6 \mathrm{~kg}\end{array}$ \\
\hline Sexo & 0,8903 & 0,0003 & 0,0015 \\
\hline Tratamento & 0,4212 & 0,7838 & 0,5950 \\
\hline Interação SxT & 0,1525 & 0,1070 & 0,1052 \\
\hline Machos castrados"|Tratamento & 0,1025 & 0,1326 & 0,0838 \\
\hline Linear & 0,6021 & $0,0237^{1}$ & $0,0493^{2}$ \\
\hline Quadrático & 0,0703 & 0,3954 & 0,1739 \\
\hline Cúbico & $0,0506^{3}$ & 0,4023 & 0,1277 \\
\hline Fêmeas"|Tratamento & 0,4312 & 0,5231 & 0,5046 \\
\hline Linear & 0,5278 & 0,5045 & 0,7736 \\
\hline Quadrático & 0,6708 & 0,2162 & 0,3931 \\
\hline Cúbico & 0,2034 & 0,3312 & 0,1372 \\
\hline \multicolumn{4}{|l|}{ Características descritivas } \\
\hline $\mathrm{R}^{2}$ do modelo & 73,93 & 78,53 & 79,25 \\
\hline C.V. (\%) & 2,56 & 2,62 & 2,07 \\
\hline Desvio padrão & 0,0634 & 0,0799 & 0,0579 \\
\hline Média geral & $2,48 \pm 0,02$ & $3,05 \pm 0,02$ & $2,80 \pm 0,02$ \\
\hline
\end{tabular}

${ }^{1} \mathrm{Na}$ terminação $y=3,19-0,17 \times \mathrm{com} \mathrm{R}^{2}=64,0$. ${ }^{2}$ No período total $y=2,83-0,10 \times$ com $R^{2}=32,3$. *No crescimento $y=2,56-1,58 X+4,68 X^{2}-3,54 X^{3}$ com $R^{2}=97,6$. 
Tabela VII. Médias e desvio padrão para a conversão alimentar $(\mathrm{g} / \mathrm{g})$ para machos castrados e fêmeas considerando o nivel de substituição do farelo de soja da dieta referência pelo farelo de canola. (Means and standard deviation for feed to gain ratio $(\mathrm{g} / \mathrm{g})$ for barrows and gilts considering the level of soybean meal substitution in the reference diet by canola meal).

\begin{tabular}{|c|c|c|c|c|c|c|c|c|c|}
\hline NS & \multicolumn{3}{|c|}{ Crescimento } & \multicolumn{3}{|c|}{$\begin{array}{c}\text { Conversão alimentar, g/g } \\
\text { Terminação }\end{array}$} & \multicolumn{3}{|c|}{ Período total } \\
\hline 0 & 2,56 & $\pm 0,07^{a}$ & $2,46 \pm 0,09$ & 3,22 & $\pm 0,08^{a}$ & $2,89 \pm 0,12$ & $2,94 \pm$ & $\pm 0,06^{a}$ & $2,71 \pm 0,09$ \\
\hline 20 & 2,41 & $\pm 0,01^{\mathrm{b}}$ & $2,54 \pm 0,03$ & $3,12=$ & $\pm 0,01^{\mathrm{ab}}$ & $2,98 \pm 0,02$ & $2,81 \pm$ & $\pm 0,01^{\mathrm{ab}}$ & $2,80 \pm 0,01$ \\
\hline 40 & 2,44 & $\pm 0,05^{\mathrm{ab}}$ & $2,44 \pm 0,05$ & $3,08=$ & $\pm 0,05^{b}$ & $3,02 \pm 0,02$ & $2,82 \pm$ & $\pm 0,05^{\mathrm{ab}}$ & $2,77 \pm 0,01$ \\
\hline 60 & 2,54 & $\pm 0,04^{a}$ & $2,42 \pm 0,04$ & $3,14=$ & $\pm 0,04^{\mathrm{ab}}$ & $2,94 \pm 0,01$ & $2,88 \pm$ & $\pm 0,03^{a b}$ & $2,70 \pm 0,03$ \\
\hline 80 & 2,48 & $\pm 0,06^{\mathrm{ab}}$ & $2,49 \pm 0,05$ & $3,04=$ & $\pm 0,08^{b}$ & $2,97 \pm 0,06$ & $2,80 \pm$ & $\pm 0,07^{b}$ & $2,75 \pm 0,02$ \\
\hline Média & 2,48 & $\pm 0,03$ & $2,47 \pm 0,02$ & 3,12 & $\pm 0,03$ & $2,79 \pm 0,06$ & $2,85=$ & $\pm 0,02$ & $2,75 \pm 0,02$ \\
\hline
\end{tabular}

NS: Nível de substituição \%.

Em cada coluna as médias com letras distintas diferem $(p<0,05)$ pelo teste $t$ de Student.

até alcançar o ápice. No teste de médias aplicado, conforme apresentado na tabela VII, os níveis de $20 \%$ e $60 \%$ de substituição do farelo de soja por canola na dieta referência diferem entre si para os machos castrados. Este resultado não se verifica para as fêmeas. O conteúdo de proteína bruta nas dietas, mais apropriado para os machos castrados do que para as fêmeas, deve ter uma influência acentuada sobre a resposta dos animais aos níveis de farelo de canola. Na fase de terminação não houve efeito significativo $(p=0,3340)$ de tratamento para ganho de peso médio diário porém, no consumo diário de ração o efeito de tratamento $(p=0,1531)$ proporcionou um ajuste quadrático $(\mathrm{p}=0,0752)$ com ponto de máxima em 34,8\% segundo a equação ajustada $\left(\mathrm{y}=2780,83+1487,62 \mathrm{X}-2134,83 \mathrm{X}^{2}\right.$, $\left.\mathrm{R}^{2}=74,25\right)$. O resultado indica que ocorre, na fase de terminação, uma limitação natural ao consumo com níveis de substituição do farelo de soja por farelo de canola acima do valor citado. Nesta fase que compreendeu, em média, o intervalo de peso de 58,7 a 102,6 $\mathrm{kg}$, os machos castrados ganharam 15,2\% mais peso que as fêmeas $(p=0,0036)$ e consumiram $21,1 \%$ a mais de ração do que as fêmeas $(p=0,0001)$. A conversão alimentar teve efeito de interação $(p=0,1070)$ entre tratamento e sexo o que possibilitou estimar uma regressão linear significativa $(p=0,023)$ para machos castrados $\left(\mathrm{y}=3,19-0,17 \mathrm{X}, \mathrm{R}^{2}=\right.$ $64,01)$ e não significância $(\mathrm{p}>0,05)$ para fêmeas. Estes resultados estão em consonância com os descritos por Li et al. (2000) que avaliaram o efeito de inclusão de farelo de canola em dietas para suínos de $58 \mathrm{~kg}$ até $91 \mathrm{~kg}$ e concluiram pela ausência de efeito sobre o ganho de peso mas, estabeleceram uma redução significativa nos valores de conversão alimentar. Gomes et al. (1998) avaliaram o desempenho de suínos na fase de terminação e concluiram que é possível efetuar a inclusão de até $15 \%$ de farelo de canola, substituindo totalmente o farelo de soja nas dietas de suínos em terminação sem afetar o ganho de peso, consumo de ração e a conversão alimentar. Os resultados apresentados também estão em concordância ao que foi relatado por Rojo et al. (2001) que indicaram a possibilidade de substituição total do farelo de canola nas dietas formuladas contendo sorgo como fonte energética na ração. $\mathrm{Na}$ análise estatística do período total para o ganho de peso diário o efeito de tratamento $(\mathrm{p}=0,1995)$ permitiu um ajuste quadrático $(\mathrm{p}=0,0382)$ e, 


\section{FARELO DE CANOLA EM DIETAS PARA SUÍNOS EM CRESCIMENTO E TERMINAÇÃO}

segundo a equação correspondente ( $\mathrm{y}=$ $\left.889,46+280,56 \mathrm{X}-364,56 \mathrm{X}^{2}, \mathrm{R}^{2}=82,39\right), \mathrm{com}$ $38,5 \%$ de substituição do farelo de soja da dieta referência por farelo de canola é estimado o máximo ganho de peso. De forma semelhante, o efeito de tratamento $(\mathrm{p}=$ $0,1677)$ para o consumo de ração permitiu um ajuste quadrático $(\mathrm{p}=0,0439)$ com a equação ( $\mathrm{y}=2533,2+622,18 \mathrm{X}-905,13 \mathrm{X}^{2}$, $\left.\mathrm{R}^{2}=78,91\right)$ indicando máximo consumo ao nível de 34,4\% de substituição. Estes dois resultados apontam de modo claro que a limitação no consumo voluntário de ração até um valor máximo alcançado no nível de $34,4 \%$ determina como conseqüência um ganho de peso máximo ao nível de substituição de $38,5 \%$. Esta limitação no consumo e ganho de peso está em consonância com os relatos feitos por Schöne et al. (2002) para suínos com alta capacidade de produção de carne porém, contrastam com os relatos de Brand et al. (2001) que não verificaram efeito de restrição no consumo e ganho de peso em níveis elevados de farelo de canola na dieta. Spiegel e Blum (1993) afirmaram que o menor consumo de ração é a causa principal para a redução na taxa de crescimento em suínos em engorda alimentados com farelo de canola. O teste de médias, apresentado na tabela $\mathbf{V}$, indica que o nível de $40 \%$ de substituição possibilita ganho de peso e consumo de ração que são superiores ao nível de $80 \%$ de substituição do farelo de soja por farelo de canola. Considerando o período total, compreendido pelos 84 dias experimentais, os machos castrados ganharam $12,2 \%$ mais peso $(p=$ $0,0005)$ e consumiram $16,1 \%$ mais ração $(\mathrm{p}<0,0001)$ do que as fêmeas. Para a conversão alimentar no período total foi verificada interação entre sexo e tratamento $(\mathrm{p}=0,1052)$ com efeito linear $(\mathrm{p}=0,049)$ para machos castrados e ausência de efeito significativo $(p>0,05)$ de tratamento para fêmeas. Segundo a equação $y=2,83-0,10 \mathrm{X}$, para cada $10 \%$ de substi-tuição do farelo de

Tabela VIII. Análise da variância para as características de carcaça em função dos tratamentos e sexo. (Analysis of variance for carcass traits considering the treatments and sex).

\begin{tabular}{|c|c|c|c|c|c|c|}
\hline & \multicolumn{6}{|c|}{ Análise estatística para as características de carcaça (valores de $p$ ) } \\
\hline & $\mathrm{PC}$ & $\mathrm{RC}$ & REC & ET & PL & PEC \\
\hline Sexo (S) & $<0,0001$ & 0,6828 & 0,0062 & 0,0037 & 0,9348 & 0,0009 \\
\hline Tratamento $(\mathrm{T})$ & 0,0296 & 0,2879 & $0,0121^{2}$ & $0,0157^{2}$ & 0,7469 & 0,0556 \\
\hline Efeito linear & 0,7386 & 0,7795 & 0,5941 & 0,5201 & 0,4510 & 0,9637 \\
\hline Efeito quadrático & $0,0059^{1}$ & 0,1252 & 0,8663 & 0,7468 & 0,3994 & $0,0065^{3}$ \\
\hline Efeito cúbico & 0,3094 & 0,2043 & 0,6597 & 0,4231 & 0,4476 & 0,4431 \\
\hline Efeito quártico & 0,2132 & 0,4689 & $<0,0001$ & $<0,0001$ & 0,8011 & 0,1997 \\
\hline Interação SxT & 0,4821 & 0,8994 & 0,7826 & 0,9713 & 0,4101 & 0,2261 \\
\hline \multicolumn{7}{|c|}{ Características descritivas } \\
\hline $\mathrm{R}^{2}$ do modelo & 88,66 & 46,40 & 73,11 & 73,78 & 43,67 & 86,30 \\
\hline C.V. $(\%)$ & 4,52 & 1,70 & 2,75 & 10,07 & 8,63 & 4,41 \\
\hline Desvio padrão & 3,28 & 1,20 & 1,43 & 2,48 & 4,52 & 1,65 \\
\hline Média geral & $72,55 \pm 1,33$ & $70,68 \pm 0,22$ & $51,78 \pm 0,37$ & $24,59 \pm 0,66$ & $52,38 \pm 0,82$ & $37,50 \pm 0,61$ \\
\hline
\end{tabular}

$\mathrm{PC}=$ Peso da carcaça, kg; RC= Rendimento de carcaça, \%; REC= Rendimento estimado de carne, \%; $\mathrm{ET}=$ Espessura de toucinho, $\mathrm{mm} ; \mathrm{PL}=$ Profundidade de lombo, $\mathrm{mm} ; \mathrm{PEC}=$ Produção estimada de carne, $\mathrm{kg}$. ${ }^{1}$ Peso da carcaça, $\mathrm{kg}\left(\mathrm{y}=70,38+24,31 \mathrm{X}-31,29 \mathrm{X}^{2}\right)$ com $\mathrm{R}^{2}=77,7$ e nível ótimo em $38,8 \%$.

${ }^{2}$ Efeito significativo para tratamento no quarto grau $(p<0,0001)$.

${ }^{3}$ Produção estimada de carne, $\mathrm{kg}\left(\mathrm{y}=36,17+13,16 \mathrm{X}-16,13 \mathrm{X}^{2}\right)$ com $\mathrm{R}^{2}=84,9$ e nível ótimo em 40,8\%. 
Tabela IX. Médias e desvio padrão para as características de carcaça considerando os tratamentos (niveis de substituição do farelo de soja da dieta referência pelo farelo de canola) e sexo. (Means and standard deviation for carcass traits considering the treatments (levels of soybean meal substitution in the reference diet by canola meal) and sex).

\begin{tabular}{lcccccc}
\hline & & \multicolumn{5}{c}{ Características de carcaça } \\
NS & PC & RC & REC & ET & PL & PEC \\
\hline 0 & $71,2 \pm 3,4^{\text {bc }}$ & $70,4 \pm 0,26$ & $51,0 \pm 1,08^{\mathrm{bc}}$ & $25,9 \pm 1,70^{\mathrm{ab}}$ & $54,0 \pm 2,2$ & $36,2 \pm 1,4^{\mathrm{bc}}$ \\
20 & $72,0 \pm 2,7^{\mathrm{bc}}$ & $70,2 \pm 0,29$ & $53,3 \pm 0,59^{\mathrm{a}}$ & $22,0 \pm 1,04^{\mathrm{c}}$ & $52,0 \pm 1,2$ & $38,3 \pm 1,2^{\mathrm{ab}}$ \\
40 & $76,4 \pm 1,9^{\mathrm{a}}$ & $71,4 \pm 0,44$ & $50,0 \pm 0,72^{\mathrm{c}}$ & $27,6 \pm 1,21^{\mathrm{a}}$ & $51,4 \pm 1,4$ & $38,2 \pm 0,9^{\mathrm{abc}}$ \\
60 & $73,9 \pm 4,3^{\mathrm{ab}}$ & $71,4 \pm 0,70$ & $52,8 \pm 0,64^{\mathrm{ab}}$ & $23,3 \pm 1,61^{\mathrm{bc}}$ & $52,9 \pm 2,9$ & $39,0 \pm 2,0^{\mathrm{a}}$ \\
80 & $69,5 \pm 3,1^{\mathrm{c}}$ & $70,1 \pm 0,60$ & $50,9 \pm 0,51^{\mathrm{ab}}$ & $23,9 \pm 0,94^{\mathrm{bc}}$ & $52,1 \pm 2,2$ & $36,1 \pm 1,5^{\mathrm{c}}$ \\
Sexo & & & & & & \\
Machos castrados & $76,9 \pm 1,2^{\mathrm{a}}$ & $70,8 \pm 0,34$ & $50,9 \pm 0,51^{\mathrm{b}}$ & $26,4 \pm 0,81^{\mathrm{a}}$ & $52,8 \pm 1,1$ & $39,1 \pm 0,7^{\mathrm{a}}$ \\
Fêmeas & $67,8 \pm 1,6^{\mathrm{b}}$ & $70,6 \pm 0,30$ & $52,8 \pm 0,42^{\mathrm{a}}$ & $22,7 \pm 0,77^{\mathrm{b}}$ & $52,0 \pm 1,3$ & $35,8 \pm 0,8^{\mathrm{b}}$ \\
\hline
\end{tabular}

NS= Nível de substituição, \%; PC= Peso da carcaça, kg; RC= Rendimento de carcaça, \%; REC= Rendimento estimado de carne, \%; ET= Espessura de toucinho, mm; PL= Profundidade de lombo, mm; $\mathrm{PEC}=$ Produção estimada de carne, $\mathrm{kg}$.

Dentro da mesma fonte de variação (nível de substituição ou sexo) em cada coluna as médias com letras distintas diferem $(p<0,05)$ pelo teste $t$ de Student.

soja por farelo de canola os machos castrados apresentam uma melhora na conversão em 0,01 unidades e desta forma para o nível máximo de substituição o valor estimado para a conversão alimentar é de 2,75. Este efeito linear para conversão alimentar está vinculado de forma acentuada com o menor consumo de ração nos níveis de 60 e $80 \%$ de substituição do farelo de soja por farelo de canola.

A análise de variância para as características de carcaça e as médias ajustadas com o seu erro padrão estão apresentadas nas tabelas VIII e IX, respectivamente. O peso da carcaça foi condicionado pelos tratamentos aplicados $(p=0,0296)$ com efeito quadrático $(\mathrm{p}=0,0059)$ no qual se estabelece através da equação $(\mathrm{y}=70,38+24,31 \mathrm{X}$ $\left.31,29 \mathrm{X}^{2}, \mathrm{R}^{2}=77,74\right)$ um ponto de máxima em $38,8 \%$ de substituição do farelo de soja da dieta referência por farelo de canola. Este valor estimado é, em grande parte, determinado pelo ganho de peso médio diário coincidindo em ambos os casos com valores de substituição do farelo de soja por farelo de canola para máximo efeito muito próximos entre si, correspondendo para ganho de peso médio diário e peso da carcaça a $38,5 \%$ e $38,8 \%$, respectivamente. Os machos castrados apresentaram carcaças $13,4 \%$ mais pesadas $(\mathrm{p}<0,0001)$ do que as fêmeas. Para o rendimento de carcaça e a profundidade do lombo não foram determinados efeitos significativos $(p>0,10)$ para nenhuma das fontes de variação avaliadas. Este resultado está de acordo com os relatos de Gomes et al. (1998) que avaliaram níveis crescentes de farelo de canola nas dietas de suínos na fase de terminação utilizando a mesma metodologia de avaliação das carcaças. A produção estimada de carne foi influenciada pelos tratamentos $(\mathrm{p}=$ $0,0556)$ com efeito quadrático $(p=0,0065)$ e conforme indica a equação $(y=36,17+13,16$ $\mathrm{X}-16,13 \mathrm{X}^{2}, \mathrm{R}^{2}=84,89$ ) com ponto de máxima em 40,8\% de substituição do farelo de soja da dieta referência por farelo de canola. A produção estimada de carne para os machos castrados é significativamente superior $(\mathrm{p}=$ 0,0009 ) do que a das fêmeas, alcançando um valor que corresponde a um incremento de $9,2 \%$. Foram verificados efeitos significati- 
vos para tratamento para as variáveis rendimento estimado de carne $(\mathrm{p}=0,0121) \mathrm{e}$ espessura de toucinho $(\mathrm{p}=0,0157)$ medida no ponto $\mathrm{P}_{2}$ com nível significativo $(\mathrm{p}<0,0001)$ para equações quárticas. $O$ ajuste da equação para rendimento estimado de carne pelo modelo completo $(\mathrm{y}=51,00+71,33 \mathrm{X}$ $\left.460,01 X^{2}+909,65 X^{3}-555,51 X^{4}\right)$ caracteriza três pontos relevantes. $\mathrm{O}$ valor mínimo estimado corresponde a $50,0 \%$ de carne na carcaça ao nível de substituição de 41,01\% do farelo de soja da dieta referência por farelo de canola. Os outros dois pontos relevantes indicam os valores máximos de rendimento de carne na carcaça, respectivamente $54,43 \%$ e $54,31 \%$, ao nível de $11,10 \%$ e $70,67 \%$ de substituição do farelo de soja por farelo de canola. De forma idêntica o ajuste da equação para espessura de toucinho $\left(y=25,92-118,54 X+753,85 X^{2}\right.$ $1473,96 \mathrm{X}^{3}+891,15 \mathrm{X}^{4}$ ) caracteriza três pontos relevantes. O valor máximo estimado corresponde a 27,62 mm de espessura de toucinho ao nível de substi-tuição de $41,62 \%$ do farelo de soja da dieta referência por farelo de canola. Os outros dois pontos relevantes indicam os valores mínimos de espessura de toucinho na carcaça, respectivamente, $20,15 \mathrm{~mm}$ e $20,66 \mathrm{~mm}$, ao nível de $11,22 \%$ e $71,21 \%$ de substituição. Os resultados similares para estes dois parâmetros ocorrem porque o rendimento estimado de carne na carcaça é uma combinação linear entre espessura de toucinho e profundidade de lombo. Os pontos relevantes determinados refletem o comportamento característico do ajuste matemático para consumo médio diário. Pois, para o maior consumo de ração existe a equivalência para maior espessura de toucinho e, em conseqüência é gerado um valor mínimo para rendimento estimado de carne na carcaça. De modo inverso, para os níveis mais baixos de consumo estimados pela regressão quadrática existe uma correspondência com os valores de mínima espessura de toucinho e, em conseqüência os correspondentes valores máximos associados para rendimento esti- mado de carne na carcaça. O ajuste de quarto grau para espessura de toucinho e rendimento estimado de carne na carcaça ocorre porque existem duas regiões, uma antes do nível de $11 \%$ e outra após o nível de $71 \%$ de substituição de farelo de soja da dieta referência por farelo de canola, em que existe a inversão na tendência de decréscimo ou aumento nos valores estimados. Na região antes do nível de $11 \%$ de substituição do farelo de soja por farelo de canola existe um efeito característico da dieta referência condicionando o desempenho com estimativa de valores baixos para consumo de ração e ganho de peso, alta conversão alimentar, alta espessura de toucinho e baixo rendimento estimado de carne na carcaça. Na região após o nível de $71 \%$ de substituição do farelo de soja por farelo de canola ocorre, devido à redução do consumo de ração, uma restrição alimentar que proporciona um menor ganho de peso e ao mesmo tempo melhora na conversão alimentar porém, com aumento na espessura de toucinho e redução no rendimento estimado de carne na carcaça. Os resultados apresentados não corroboram aqueles relatados por Roth-Maier et al. (2004) e Thacker e Newkirk (2005) que não evidenciaram efeito de nível de farelo de canola substituindo o farelo de soja em dietas para suínos nas fases de crescimento e terminação sobre qualquer das características de carcaça avaliadas. Gomes et al. (1998) determinaram ausência de efeito de nível de farelo de canola na dieta de suínos na fase de terminação para o peso da carcaça, espessura de toucinho e rendimento estimado de carne na carcaça.

Em síntese o presente experimento demonstra o efeito de piora na conversão alimentar na fase de crescimento e uma limitação no consumo na fase de terminação quando níveis altos de farelo de canola são incluídos em substituição do farelo de soja. $\mathrm{Na}$ análise do período total é possível demonstrar um efeito em que a combinação entre farelo de soja e farelo de canola produz os melhores resultados para ganho de peso. 


\section{ZANOTTO, LUDKE, GUIDONI, GOMES, BRUM E AJALA}

A inversão nos resultados da conversão alimentar da fase de crescimento para a fase de terminação e período total deve-se ao fato de que a limitação do consumo nos períodos de engorda e total proporciona uma restrição alimentar o que conduz à melhora na conversão. As características de carcaça indicam para a maior produção estimada de carne quando o farelo de soja e

\section{BIBLIOGRAFIA}

AOAC. 1990. Official methods of analysis. $16 \mathrm{ed}$ Washington D.C. 1136 p.

Baidoo, S.K., F.X. Aherne, B.N. Mitaru and R. Blair. 1987. Canola meal as a protein supplement for growing-finishing pigs. Anim. Feed Sci. Tech., 18: 37-44.

Bell, J.M. and M.O. Keith. 1987. Feeding value for pigs of canola meal derived from Westar and triazine-tolerant cultivars. Can. J. Anim. Sci., 67: 811-819.

Bell, J.M., M.O. Keith and D.S. Hutcheson. 1991. Nutritional evaluation of very low glucosinolate canola meal. Can. J. Anim. Sci., 71: 497-506.

Bourdon, D. and A. Aumaitre. 1990. Lowglucosinolate rapeseeds and rapeseed meals: effect of technological treatments on chemica composition, digestible energy content and feeding value for growing pigs. Anim. Feed Sci. Tech., 30: 175-191.

Brand, T.S., D.A. Brandt and C.W. Cruywagen. 2001. Utilisation of growing-finishing pig diets containing high levels of solvent or expeller oil extracted canola meal. New Zeal. J. Agr. Res., 44: 31-35.

Canola Council of Canada. 1989. Canadian canola meal: Maximum inclusion rates. Canola Council of Canada. Winnipeg. Canada.

Gomes, P.C., D.L. Zanotto, A.L. Guidoni, M.F.M. Gomes e A.H. Nascimento. 1998. Uso do farelo de canola para suínos na fase de terminação. Rev. Bras. Zootecn., 27: 749-753.

Li, D., S.Y. Qiao, G.F. Yi, J.Y. Jiang, X.X. Xu, P. Thacker, X.S. Piao and I.K. Han. 2000. Nutritive evaluation of chinese nonconventional protein de canola são combinados o que traz em conseqüência a produção de carcaças com menor rendimento estimado de carne.

\section{CONCLUSÃO}

O farelo de canola pode ser incluído nas dietas de suínos em crescimento e terminação ao nível de substituição de $40 \%$ do farelo de soja.

feedstuffs for growing-finishing pigs - 2 . Rapeseed meal. Asian-Austral. J. Anim., 13: 46-52.

Rojo, G.A., M.V.G. Perez, U.A. Bayardo, C.H.J. Correa and I.J.A. Cuáron. 2001. Canola meal as a protein supplement in diets for finishing pigs. Téc. Pec. Méx., 39: 179-192.

Roth-Maier, D.A., B.M. Böhmer and F.X. Roth. 2004. Effects of feeding canola meal and sweet lupin (L. luteus, L. angustifolius) in amino acid balanced diets on growth performance and carcass characteristics of growing-finishing pigs. Anim. Res., 54: 21-34.

SAS/STAT. 1993. User's Guide. Version 6. $4^{\mathrm{a}} \mathrm{Ed}$. SAS Institute Inc. Cary NC. USA. 1686 p.

Schöne, F., F. Tischendorf, U. Kirchheim, W. Reinhardt and J. Bargholz. 2002. Effect of high fat rapeseed press cake on growth, carcass, meat quality and body fat composition of leaner and fatter pig crossbreeds. Anim. Sci., 74: 285297.

Spiegel, C. and J.W. Blum. 1993. Lower food intake is a primary cause of reduced growth rate in growing pigs fed rapeseed presscake meal. J. Nutr., 123: 1562-1566.

Thacker, P.A. 1990. Canola meal. In: Thacker, P.A.; Kirkwood, R.N. ed. Non-traditional feed sources for use in swine production. Department of Animal and Poultry Science. University of Saskatchewan. Canada. p. 69-78.

Thacker, P.A. and R.W. Newkirk. 2005. Performance of growing-finishing pigs fed barleybased diets containing toasted or non-toasted canola meal. Can. J. Anim. Sci., 85: 53-59. 